[1] Kravitz H, Katz R. Fibrofog and fibromyalgia: a narrative review and implications for clinical practice. Rheumatology International. 2015;35(7):1115-25.

Acknowledgments: This work is supported by the National Institute for Heath Research [ICA-PCAF-2018-01-078 to SD]

Disclosure of Interests: Sandra Derham: None declared, Jenny Lewis: None declared, Emma Dures Grant/research support from: Independent Learning Grant from Pfizer, combined funding for a research fellow from Celgene, Abbvie and Novartis, Paid instructor for: A fee from Novartis to deliver training to nurses., Fiona Cramp: None declared

DOI: 10.1136/annrheumdis-2020-eular.2119

\section{SAT0624-HPR THE IMPACT OF PSORIATIC ARTHRITIS ON FOOT HEALTH AND INDICATION OF PODIATRY NEED IN A SECONDARY CARE SETTING}

R. Field ${ }^{1}$, S. Bannon ${ }^{2}$, K. Pouliase ${ }^{3}$, S. Mukherjee ${ }^{4} .{ }^{1}$ Dorset HealthCare University Foundation Trust, Bournemouth, United Kingdom; ${ }^{2}$ Dorset Healthcare University Foundation Trust, Podiatry, Bournemouth, United Kingdom; ${ }^{3}$ Dorset Healthcare University Foundation Trust, Bournemouth, United Kingdom; ${ }^{4}$ Royal Bournemouth \& Christchurch NHS Foundation Trust, Bournemouth, United Kingdom

Background: Psoriatic Arthritis (PsA) is a rheumatic disease affecting $0.19 \%$ of the UK population (1). It is characterised by asymmetric oligoarticular or polyarticular peripheral arthritis or axial disease with or without associated peripheral arthritis (2). Foot manifestations of synovitis, enthesitis, dactylitis and skin and nail involvement (3) are reported. Hyslop et al. have previously reported high levels of foot involvement but low current access to foot care (4). Outcome measures that include specific PsA related foot features do exist, e.g. Leeds Enthesitis Index, Tender Dactylitis Count (5). However there is currently no measure of foot involvement and impact in PsA (6).

Objectives: To identify the impact of PsA on foot health and indication of podiatry need in a secondary care outpatient setting

Methods: convenience sample was taken from a consultant rheumatologist's outpatient clinic and screened. Only those with a diagnosis of PsA were included. Sampling was conducted over a ten-week period. Screening was done using the Swindon Foot and Ankle Questionnaire (SFAQ) (7), visual Analogue Scale (VAS), clinical judgement of need for podiatric intervention and the trust's eligibility criteria for routine podiatric care.

Results: The sample $(n=16)$ was $31.3 \%$ male with a median age of 59 years (range 28-81).

Table 1. Footcare/Podiatric need identified

\begin{tabular}{lc}
\hline & Percentage (\%) \\
\hline Orthotic intervention, acute or routine care & 81.3 \\
Already being met & 25.0 \\
Eligible for care in podiatry primary care service & 81.3 \\
\hline
\end{tabular}

Table 2. SFAQ results

\begin{tabular}{lc}
\hline & $\begin{array}{c}\text { Percentage } \\
\text { Yes (\%) }\end{array}$ \\
\hline During the past week have your feet or ankles: & 68.8 \\
Been painful? & 62.5 \\
Been Swollen? & 81.3 \\
Made walking difficult? & 50.0 \\
Made standing up difficult? & 27.3 \\
Stopped you going to work? & 42.9 \\
Made other daily activities difficult? & 31.3 \\
Do your shoes rub the skin on your feet or ankles? & 50.0 \\
Do you have callus or hard, dry skin? & 25.0 \\
Have you had your footwear adapted or insoles made? & 18.8 \\
Have you had surgery, or are you waiting for surgery, on your feet or ankles? & \\
\hline
\end{tabular}

Conclusion: Of this patient group, $81.3 \%$ had a variety of foot care needs but these were being met in a limited number of cases (25\%). Far more patients $(81.3 \%)$ were eligible for care in the local trust's primary care podiatry service but were not engaging with this. $50 \%$ of the sample reported difficulty standing in the past week and $27.3 \%$ found their foot pain stopped them from going to work, indicating a clear need for foot health intervention.

Recommendations:

-Raise awareness of availability of podiatric care for PsA patients among patients and secondary care staff.

- Ensure adequate resources are allocated to manage this cohort of patients at a service provision level.

- Further research involving PsA patients referred into podiatry to assess the impact of podiatric intervention.

References:
[1] Ogdie A et al.(2012) Prevalence and treatment patterns of psoriatic arthritis in the UK. Rheumatology. 7;52(3):568-75.

[2] Cantini F, et al.(2010) Psoriatic arthritis: a systematic review. Int J Rheum Dis.13(4):300-17.

[3] Huynh D and Kavanaugh A. (2015) Psoriatic arthritis: current therapy and future approaches. Rheumatology. 54:20-8.

[4] Hyslop E et al. (2010) Foot problems in psoriatic arthritis: high burden and low care provision.Ann Rheum Dis.69(5):928

[5] Assessing psoriatic arthritis in your clinic - trainer manual. $2017 \mathrm{https}: / / \mathrm{www}$ psoriatic-arthritis.co.uk/assessmenttools.aspx (accessed 22-6-19)

[6] Carter $\mathrm{K}$ et al. (2019) Linking the patient experience of foot involvemen related to psoriatic arthritis to the international classification of functioning, disability and health. EULAR poster abstract THU0713-HPR

[7] Waller R et al. (2012) The swindon foot and ankle questionnaire: is a picture worth a thousand words?. ISRN rheumatology. 26;2012.

Disclosure of Interests: None declared

DOI: 10.1136/annrheumdis-2020-eular.5613

\section{SAT0625-HPR FATIGUE AND CONTRIBUTING FACTORS IN CHINESE} PATIENTS WITH ANKYLOSING SPONDYLITIS

W. Zhou ${ }^{1}$, J. Guo ${ }^{1}$, R. Zhao ${ }^{1}$, C. Dong ${ }^{1}$, Z. Gu ${ }^{1} .{ }^{1}$ Affiliated Hospital of Nantong University, Nantong, China

Background: Ankylosing spondylitis (AS) is a systemic chronic inflammatory disease, which most likely occurs in young men. It mainly affects sacroiliac joints, axia skeleton, thoracic cage and seriously decreasing quality of life in AS patients[1,2] In recent years, fatigue of $A S$ patients has been paid more and more attention[3] Fatigue is a complex feeling, diseased individuals describe fatigue as a sense of tiredness at rest, exhaustion with activity, lack of energy which affects daily work inertia or lack of endurance, or as loss of vitality. It has been confirmed that fatigue is not only a symptom but may also be quantified by fatigue scores and can be modified by various measures depending on the underlying cause[4]. However, there has been no study about fatigue in AS patients in China.

Objectives: This study aimed to evaluate the predictors of fatigue and the effects of fatigue on HR-QoL among patients with AS.

Methods: A total of 150 AS patients were involved in the study. A series of questionnaires included: Bath Ankylosing Spondylitis Disease Activity Index (BASDAI), Bath Ankylosing Spondylitis Metrology Index (BASMI), Bath Ankylosing Spondylitis Functional Index (BASFI), the $10 \mathrm{~cm}$ Visual Analog Scale (VAS) the Self-Rating Anxiety Scale (SAS), the Self-Rating Depression Scale (SDS) the Pittsburgh Sleep Quality Index (PSQI), the Health Assessment Questionnaire-Disability Index (HAQ-DI), the Short Form 36 Health Survey (SF-36) and the Fatigue Severity Scale(FSS). Independent samples t-test, Mann-Whitney U-test, Chi-square analysis, Pearson /Spearman correlation and binary logistic regression were used to analyze the data.

Results: The results demonstrated that $48.7 \%$ individuals with AS suffered from fatigue. Compared with AS patients without fatigue, AS patients with fatigue showed higher WHR $(P<0.05)$, increased BASDAI $(P<0.01)$ and poorer BASFI $(P<0.05)$. Meanwhile, AS patients with fatigue tended to have more severe pain $(P<0.05)$, higher degree of anxiety $(P=0.001)$, more serious functional disability $(P=0.001)$ and worse sleep quality $(P=0.001)$. Binary logistic regression indicated that WHR $(\mathrm{OR}=1.78, P<0.05)$, BASDAI (OR=1.34, $P=0.01)$, sleep disturbance $(\mathrm{OR}=2.35, P<0.05)$ were independent predictors of fatigue in AS patients. Additionally, the occurrence of fatigue significantly reduced the quality of life in AS patients both physically and psychologically.

Conclusion: These findings suggested that medical personnel should pay more attention to AS patients with fatigue and take effective measures to relieve fatigue. References:

[1] Law L, Beckman Rehnman J, Deminger A, Klingberg E, Jacobsson LTH Forsblad-d'Elia $\mathrm{H}$ (2018) Factors related to health-related quality of life in ankylosing spondylitis, overall and stratified by sex. Arthritis research \& therapy 20 (1):284. doi:10.1186/s13075-018-1784-8

[2] Hanson A, Brown MA (2017) Genetics and the Causes of Ankylosing Spondylitis. Rheumatic diseases clinics of North America 43 (3):401-414 doi:10.1016/j.rdc.2017.04.006

[3] Ulus Y, Akyol Y, Bilgici A, Kuru O (2019) Association of work instability with fatigue and emotional status in patients with ankylosing spondylitis: comparison with healthy controls. Clinical rheumatology 38 (4):1017-1024 doi:10.1007/s10067-018-4366-x

[4] Finsterer J, Mahjoub SZ (2014) Fatigue in healthy and diseased individuals. The American journal of hospice \& palliative care 31 (5):562-575. doi:10.1177/1049909113494748

Acknowledgments: Thanks to all the authors for their efforts and thanks to all members of the Department of Rheumatology of Affiliated Hospital of Nantong University for their helpfulness in the acquisition of data.

Disclosure of Interests: None declared

DOI: 10.1136/annrheumdis-2020-eular.6313 